\begin{tabular}{c} 
Volume and Issues Obtainable at Center for Sustainability Research and Consultancy \\
Responsible Education, Learning and Teaching in Emerging Economies \\
ISSN: 2708-4310 (E): 2708-4183 \\
Volume 1: No. 1, June 2019 \\
CSRᄃ \\
Journal homepage: www.publishing.globalcsrc.org/relate \\
\hline
\end{tabular}

\title{
Development of Fine Motor Skills to Enhance the Functional Abilities of Children With Cerebral Palsy
}

\author{
${ }^{1}$ Samina Ashraf, ${ }^{2}$ Farheen Nisar
}

${ }^{1}$ Assistant Professor, Lahore Leads University, Lahore, Pakistan: miss_saminadse@yahoo.com

${ }^{2}$ M.Phil scholar, Lahore Leads University, Lahore, Pakistan

\begin{tabular}{l} 
ARTICLE DETAILS \\
\hline History \\
Revised format: May 2019 \\
Available Online: June 2019
\end{tabular}

\section{Keywords}

Cerebral Palsy, Fine Motor

Skills, Physical Disability

\section{JEL Classification:}

O23, E11

\section{ABSTRACT}

Cerebral palsy is a neurological, non-progressive and commonest cause of severe physical disabilities. It affects body movement and muscle coordination permanently and usually appears in early childhood. Children with cerebral palsy have severe problems of fine motor skills. The research was conducted to achieve the following objectives 1) to identify the current level of fine motor skills of students with cerebral palsy studying in the schools, 2)Design an intervention strategic plan to enhance the fine motor skills of children with cerebral palsy,3)implement the prescribed intervention plan to enhance the fine motor skills of children with cerebral palsy.4)improve the fine motor skills of children with cerebral palsy by implementing the intervention strategies. It was an experimental research conducted by applying single subject research design (ABA).The researchers used two different checklists to assess the functional abilities of the children with $\mathrm{CP}$ before and after intervention. The reliability of all the instruments was checked by using cronbach alpha (.87 and .78) whereas the content validity of the instruments was estimated by taking expert opinions. On the basis of pretest an intervention plan was implemented to enhance the functional abilities of the students. A self-developed test was used after implementing the intervention strategies to see the improvement in the functional abilities of children with cerebral palsy.

\section{OPEN ACCESS}

(C) 2019 The authors, under a Creative Commons Attribution-

NonCommercial 4.0

Corresponding author's email address: miss_saminadse@ yahoo.com

Recommended citation: Ashraf, S. \& Nisar, F (2019). Development of Fine Motor Skills to Enhance the Functional Abilities of Children With Cerebral Palsy. Responsible Education, Learning and Teaching in Emerging Economies, 1(1), 31-36

DOI: $10.26710 /$ relate.v1i1.1120

\section{Introduction}

Cerebral palsy is a most common cause of severe motor disability in childhood (Stavsky, Mor, Mastrolia, Greenbaum, Than, and Erez, 2017). It is a neurological, life span motor disorder and affects body 
movement and muscle coordination (Stavsky, et al. 2017; Morgan \& McGinley, 2018). People with cerebral palsy faced problems in functional motilities, usually characterized with spasticity e.g; contractures, as well as they face problems in the processing of sensory information (Morgan \& McGinley, 2018).

Lower gestational age is a major factor for the onset of C.P, especially premature birth (Stavsky, et al. 2017). Lower birth weight and pre-term is also closely associated with cerebral palsy (Van Lieshout, Candundo, Martino, Shin \& Barakat-Haddad, 2017). Oskoui, Coutinho, Dykeman, Jetté \& Pringsheim (2013) conducted a systemic review and meta-analysis, their study revealed highest prevalence rate of cerebral palsy is found in lower gestational age births, "111.80 per 1000 live births".

Cerebral Palsy have not one reason for diagnosis and classification, even similar cause create aberrant posture of C.P. It has a broad range of factors that represent C.P, like: "type, severity, and bodily distribution of primary motor impairment, associated non-motor neurologic and behavioral impairments, functional deficits, and cerebral pathology (McAdams \& Juul, 2011). Due to this variability and different patterns, it is categorized according to phenotypic subtypes e.g.; type of tone abnormality (as spastic, ataxic, or dyskinesia/athetoid), distribution of limb weakness (as bilateral or unilateral). Spastic is a common type among preterm born children (Hack \& Costello, 2008). According to distribution of limb weakness Farrell (2008) grouped C.P into: quadriplegia, all the four limbs and body are equally affected, hemiplegia, one half of the body is affected, paraplegia, in which either the arms or the legs are affected, diplegia, involvement of whole body but lower half. (Brewis, Farrell, 2008) also grouped C.P. into phenotypic subtypes: spasticity, athetoid, and ataxic.

Fine motor activities (grasping with hand, finger and arms) start in utero, and in first few years of life. Movement of hand, arms and fingers is very important throughout the human life for completing many functional task Morris \& Whishaw, (2015). By using fine motor skills children grasp and manipulate many objects, and extend their manual abilities. And later on these manual abilities connect to various cognitive skills such as writing and playing. It is also important for socialization, affection, communication and gestural expression (Ritter \& Haschke, 2015). But the severe neurological conditions, can greatly affect individuals life and his/her fine motor movements (Morris \& Whishaw, 2015).

The previous researches revealed if we provide different interventions, novel method and targeted treatment to upper limb of children with cerebral palsy, it will improve motor movement (bimanual performance) and cognition of the children (2018). Children with cerebral palsy often have tactile problems. Intensive bimanual training with tactile material can improve tactile spatial resolution in children with spastic cerebral palsy (Kuo, Gordon, Henrionnet, Hautfenne, Friel \& Bleyenheuft,2016).

There is evidence that interventions and individualized exercise program with sufficient duration and intensity improve the functional balance and mobility of adult with cerebral palsy (Morgan \& McGinley,2018). Motor development in children with cerebral palsy is very important, this study focuses on the development of fine motor skills for enhancing functional abilities of children with cerebral palsy. Development of these functional abilities is utmost necessary for the academic skills of children with cerebral palsy.

\section{Research Design}

This study is experimental in nature. For this purpose A-B-A research design was selected for the development of fine motor skills. 


\subsection{Experimental design of study}

\begin{tabular}{|l|l|l|l|l|}
\hline $\begin{array}{l}\text { Random } \\
\text { Selection }\end{array}$ & $\mathbf{N}=\mathbf{5}$ & Baseline & Intervention & Baseline \\
\hline
\end{tabular}

\subsection{Population of the study}

The population of the study consisted of 7 to 12 years old children with cerebral palsy of the city Faisalabad of Pakistan. There are 15 government special education schools in Faisalabad. Researcher personally conducted a survey and find there are 51 children that have cerebral palsy out of 170 children with physical disability.

\subsection{Sample of the study}

The researchers took $10 \%$ children with cerebral palsy from the special education schools of Faisalabad. Researchers have selected two schools of special education by using simple random sampling technique belting. A number of 5 children had selected randomly out of 51 children and matched the sample on two characteristics: 1) class, and 2) age. All children were taken from K.G 1 class that has age range between 7 to 12 years old and all of them have good eyesight and onset of disability by birth. Majority students except the one had varied degree of intellectual and speech impairment mild level to severe level. Among the selected sample, 4 students are male and 1 student is female, majority of the students were athetoid.

\subsection{Instruments of the study}

For the development of fine motor skills, researchers used six intervention strategies for fine motor skills. For assessing fine motor skills the researchers used self-made checklists and a test was used for assessing the functional abilities of children with cerebral palsy.

\subsection{Checklist}

The researchers constructed 2 different checklists to assess the fine motor skills. Checklists comprised of two parts. First part consisted of demographic information e.g. gender, age, school entry age, onset of disability, strengths of the student, type of disability, degree of impairment, speech impairment, degree of intellectual impairment, qualification of parents, associated disabilities, body posture, body control and mobility, and second part of these checklists consisted of eighteen(18) fine motors skills items. The researcher used five point scales to rate the students' performance on each skill.

\subsection{Test for the Assessment of Functional Abilities}

The researchers used self-made test after the completion of intervention for assessing functional abilities of children with CP. The test was consisted on five questions related to their academic skills. Each test was of twenty five marks.

Content validity was checked by getting expert opinions. Researcher used the Cronbach Alpha Test to find the reliability of the research instruments. The reliability estimated after pre- test was.87 and after post-test .78 which is considered the good reliability of the instrument.

\subsection{Data collection}

Data was collected through pre and posttest followed by experimentation, from a group of 5 children with cerebral palsy in two Government Special Education schools of Faisalabad. A pretest was conducted for assessing and establishing baseline of fine motor skills. After establishing baseline, intervention was given to children with $\mathrm{CP}$, during the consecutive three months.

The intervention was consisted on strategies for the development of fine motor skills like poking straws into holes, threading and posting, mask making and playdough cupcakes. Researchers has given this treatment three months consecutively, total 180 hours had given for the development of fine motor skills.(90 minute session for one day). After intervention, a posttest was conducted with the help of check 
list, for assessing the improvement in fine motor skills. A test was used for assessing the functional abilities of children with cerebral palsy.

\subsection{Data analysis and interpretation}

The data was analyzed through Microsoft excel 2010 and SPSS. Progress of Pre and Posttest and baseline periods was shown through bar and line Graph. Wilcoxon signed ranked test was used to see the significant mean difference between Pre and Posttest.

\section{Findings}

On the basis of data analysis these findings were achieved:

Results show that all children with cerebral palsy improve fine motor skills required for their academics after under-going intervention.

Table 1: Mean summary table of student 1-5 on pre and posttest

\begin{tabular}{|l|l|l|}
\hline $\begin{array}{l}\text { Student } \\
\text { No }\end{array}$ & Pre-test & Post-test \\
\hline 1 & 1.97 & 4.34 \\
\hline 2 & 1.2 & 2.73 \\
\hline 3 & 1.97 & 4.22 \\
\hline 4 & 1.89 & 3.6 \\
\hline 5 & 2.5 & 4.34 \\
\hline
\end{tabular}

Wilcoxon Signed Rank Test revealed a statistically significant difference in pre and post intervention scores with a large effect size.

Table 2: Wilcoxon Signed Rank Test

\begin{tabular}{|l|l|l|l|l|}
\hline & $\mathbf{N}$ & & Percentiles & \\
\hline & & $25^{\text {th }}$ & $\begin{array}{l}50^{\text {th }} \\
\text { (Median) }\end{array}$ & $75^{\text {th }}$ \\
\hline Pre-test & 25 & 66.00 & 76.00 & 88.50 \\
\hline Post-test & 25 & 124.00 & 137.00 & 157.50 \\
\hline
\end{tabular}

\begin{tabular}{|l|l|}
\hline & Pre-test \\
\hline & Post-test \\
\hline $\mathbf{Z}$ & -4.374 \\
\hline $\begin{array}{l}\text { Asymp. Sig. } \\
\text { (2-tailed) }\end{array}$ & .000 \\
\hline
\end{tabular}

Table 3: Percentage on functional abilities of student 1-5

\begin{tabular}{|l|l|l|}
\hline Sr.no & $\begin{array}{l}\text { Student } \\
\text { No }\end{array}$ & $\begin{array}{l}\text { Percentage } \\
\%\end{array}$ \\
\hline 1 & 1 & $68 \%$ \\
\hline 2 & 2 & $52 \%$ \\
\hline 3 & 3 & $72 \%$ \\
\hline 4 & 4 & $56 \%$ \\
\hline 5 & 5 & $78 \%$ \\
\hline
\end{tabular}




\section{Discussion}

This study was concerned with the development of fine motor skills of children with cerebral palsy. Fine motor skills are the movement of hand, arms and fingers, and it is very important throughout the human life for completing many functional task (Morris \& Whishaw, 2015). Children enhance their manual abilities by using fine motor skills, and these manual abilities are connected with many cognitive skills (Ritter \& Haschke,2015).

Hoare, et al. (2018) conducted a study to see how cognition affects bimanual performance (fine motor skills) of children with cerebral palsy. Their study indicate after undergoing targeted treatment and intervention children with cerebral palsy improved their motor movement (of upper limbs) and cognition.

Therefore, this study was conducted for the development of fine motor skills of children with $\mathrm{CP}$ to enhance their functional abilities. Results of this study show that all children with CP improve fine motor skills after under-going experiment and enhance their functional abilities required for their academic skills. There is also statistically significant difference in pre and post test scores with a large effect size. Every student improved fine motor skills after undergoing experiment but the level of improvement of each student is varied from one another.

\section{Recommendation}

On the basis of results of the study following recommendations have been made:

- Ministries of Special Education should create seats of physiotherapist and occupational therapist in all institutions of special education.

- School heads or higher administration should arrange such materials and environment in which children's with cerebral palsy develop their motor skills.

- Short courses on the development of fine motor skills of children with cerebral palsy and diplomas should be encouraged in all types of teacher training programs.

- If physiotherapist or occupational therapists are not available then personal assistance must be provided to the teachers for the development of fine motor skills of children with cerebral palsy.

- School heads should arrange teacher training workshops for giving the awareness in teachers and parents, how to develop fine motor skills in children with cerebral palsy.

- Development of fine motor skills should be taught in curriculum of children with CP with some adaptations in curriculum and evaluation procedures.

\section{References}

Ayyub, A., Khan, A.A., \& Ahmed, K. (2014). Bone Mineral Density of Children with Cerebral Palsy in the Age Group 7 to 14 Years. Pacific Journal of Medical Sciences, vol. 3, No. 1.

Brewis, L. (2008). Including Childern with Cerebral Palsy in the Early Years Foundation Stage. Featherstone Education Limited.

Farrell, M. (2008). Educating Special Childern. New york \& London: Routledge.

Hack, M., Costello, D. W., (2008). Trends in the rates of cerebral palsy associated with neonatal intensive care of preterm children. Clin Obstet Gynecol, vol. 51, pp: 763-774.

Hoare, B., Ditchfield, M., Thorley, M., Wallen, M., Bracken, J., Harvey, A., Elliott, C., Novak, I., \& Crichton, A. (2018). Cognition and bimanual performance in children with unilateral cerebral palsy: protocol for a multicentre, cross-sectional study. BMC Neurol, vol. 18 (1).

Kim Van Naarden Braun, K.V.N., Doernberg, N., Schieve, L., Christensen, D., Goodman, A., \& YearginAllsopp, M. (2016). Birth Prevalence of Cerebral Palsy: A Population-Based Study. Pediatrics, vol, 137 (1).

Kuo, H.C., Gordon, A.M., Henrionnet, A., Hautfenne, S., Friel, K.M., \& Bleyenheuft, Y. (2016). The effects of intensive bimanual training with and without tactile training on tactile function in children with unilateral spastic cerebral palsy: A pilot study. Res Dev Disabil, pp: 49-50: 129-139.

McAdams,M. R., \& Juul,E. S. (2011). Cerebral Palsy: Prevalence, Predictability, and Parental 
Counseling. NeoReviews, vol. 12(10).

Morgan, P., \& McGinley, J. L. (2018). Handbook of Clinical Neurology: Chapter 20 - Cerebral palsy. Elsevier B.V

Morris, R., \& Whishaw, I. Q. (2015). Arm and Hand Movement: Current Knowledge and Future Perspective. Frontiers in neurology, vol, 6 (19).

Oskoui, M., Coutinho, F., Dykeman, J., Jetté, N., \& Pringsheim, T. (2013). An update on the prevalence of cerebral palsy: a systematic review and meta-analysis. Development medicine and child neurology, vol. 55 (6), pp. 509-519.

Ritter, H., \& Haschke, R. (2015). Hands, Dexterity, and the Brain, 3rd chapter. Taylor \& Francis.

Stavsky, M., Mor, O., Mastrolia, S. A., Greenbaum, S., Nandor Gabor Than, N. G., \& Erez, O. (2017). Cerebral Palsy-Trends in Epidemiology and Recent Development in Prenatal Mechanisms of Disease, Treatment, and Prevention. Front Pediatr, 5: 21.

Van Lieshout, P., Candundo, H., Martino, R., Shin, S., \& Barakat-Haddad, C. (2017). Onset factors in cerebral palsy: A systematic review. Neurotoxicology: Elsevier B.V, Jul;61:47-53. 